Delft University of Technology

\title{
Integrated PV Charging of EV Fleet Based on Energy Prices, V2G and Offer of Reserves
}

Chandra Mouli, Gautham Ram; Kefayati, Mahdi; Baldick, Ross; Bauer, Pavol

DOI

10.1109/TSG.2017.2763683

Publication date

2019

Document Version

Final published version

Published in

IEEE Transactions on Smart Grid

\section{Citation (APA)}

Chandra Mouli, G. R., Kefayati, M., Baldick, R., \& Bauer, P. (2019). Integrated PV Charging of EV Fleet

Based on Energy Prices, V2G and Offer of Reserves. IEEE Transactions on Smart Grid, 10(2), 1313-1325. [8068996]. https://doi.org/10.1109/TSG.2017.2763683

\section{Important note}

To cite this publication, please use the final published version (if applicable).

Please check the document version above.

\section{Copyright}

Other than for strictly personal use, it is not permitted to download, forward or distribute the text or part of it, without the consent of the author(s) and/or copyright holder(s), unless the work is under an open content license such as Creative Commons.

\section{Takedown policy}

Please contact us and provide details if you believe this document breaches copyrights.

We will remove access to the work immediately and investigate your claim. 
Green Open Access added to TU Delft Institutional Repository 'You share, we take care!' - Taverne project

\section{https://www.openaccess.nl/en/you-share-we-take-care}

Otherwise as indicated in the copyright section: the publisher is the copyright holder of this work and the author uses the Dutch legislation to make this work public. 


\title{
Integrated PV Charging of EV Fleet Based on Energy Prices, V2G, and Offer of Reserves
}

\author{
Gautham Ram Chandra Mouli ${ }^{\circledR}$, Student Member, IEEE, Mahdi Kefayati, Member, IEEE, \\ Ross Baldick, Fellow, IEEE, and Pavol Bauer, Senior Member, IEEE
}

\begin{abstract}
Workplace charging of electric vehicles (EVs) from photovoltaic (PV) panels installed on an office building can provide several benefits. This includes the local production and use of PV energy for charging the EV and making use of dynamic tariffs from the grid to schedule the energy exchange with the grid. The long parking time at the workplace provides the chance for the EV to support the grid via vehicle-to-grid technology, the use of a single EV charger for charging several EVs by multiplexing and the offer of ancillary services to the grid for up and down regulation. Further, distribution network constraints can be considered to limit the power and prevent the overloading of the grid. A single mixed integer linear programming (MILP) formulation that considers all the above applications has been proposed in this paper for a charging a fleet of EVs from PV. The MILP is implemented as a receding-horizon model predictive energy management system. Numerical simulations based on market and PV data in Austin, TX, USA, have shown 32\% to $651 \%$ reduction in the net cost of $\mathrm{EV}$ charging from PV when compared to immediate and average rate charging policies.
\end{abstract}

Index Terms-Charging station, distribution system, electric vehicle, photovoltaic system, regulation services, scheduling, smart charging, smart grids.

\section{NOMENCLATURE}

$\begin{array}{ll}t, v, c & - \text { Optimization indices for time, electric } \\ x_{v}^{e(a r)} & \text { vehicle (EV), and charger respectively } \\ & - \text { 'Average rate' charging power of } v^{\text {th }} \mathrm{EV} \\ t_{v}^{d l y} & (\mathrm{~kW}) \\ & - \text { Time delay for randomly delayed charg- } \\ C^{a r}, C^{\text {rnd }}, & \text { ing (h) } \\ C^{\text {imm }}, C^{\text {opt }} & - \text { Net costs for average rate, randomly } \\ & \text { delayed, immediate and optimized charg- } \\ & \text { ing from PV }(\$)\end{array}$

Manuscript received March 31, 2017; revised June 26, 2017 and September 7, 2017; accepted October 4, 2017. Date of publication October 16, 2017; date of current version February 18, 2019. This work was supported in part by the TKI Switch2SmartGrids, The Netherlands, and in part by the Partners for International Business Program of the Rijksdienst voor Ondernemend, The Netherlands. Paper no. TSG-00446-2017. (Corresponding author: Gautham Ram Chandra Mouli.)

G. R. Chandra Mouli and P. Bauer are with the Department of Electrical Sustainable Energy, Delft University of Technology, 2628 CD Delft, The Netherlands (e-mail: g.r.chandamouli@tudelft.nl; p.bauer@tudelft.nl).

R. Baldick is with the Department of Electrical and Computer Engineering, University of Texas at Austin, Austin, TX 78712 USA (e-mail: baldick@ece.utexas.edu).

M. Kefayati is with Electric Power Engineers, Inc., Bee Cave, TX, USA, and also with the Department of Electrical and Computer Engineering, University of Texas at Austin, Austin, TX 78712 USA (e-mail: kefayati@utexas.edu).

Color versions of one or more of the figures in this paper are available online at http://ieeexplore.iee.org.

Digital Object Identifier 10.1109/TSG.2017.2763683
$C^{e v}$
$S^{P V}$
$S^{a s}$
- Charging costs for entire EV fleet $(\$)$
- Revenue from sales of PV power (\$)
- Revenue from sales of regulation ser- vices $(\$)$.

\section{Optimization Input Parameters}

Electric Vehicle Parameters (Index v):

$T_{v}^{a}, T_{v}^{d} \quad-$ Arrival and departure time of EV respectively (h)

$B_{v}^{a} \quad-$ State of charge of $v^{\text {th }}$ EV upon arrival $T_{v}^{a}(\mathrm{kWh})$

$B_{v}^{d} \quad-$ State of charge of $v^{\text {th }} \mathrm{EV}$ at departure

$T_{v}^{d}(\mathrm{kWh})$

$d_{v} \quad-$ Charging energy demand of $v^{\text {th }}$

$\begin{array}{ll}C_{v}^{p} & \text { EV }(\mathrm{kWh}) \\ & - \text { Penalty for not meeting energy demand }\end{array}$ $d_{v}$ by departure time $T_{v}^{d}$ of $v^{\text {th }} \mathrm{EV}(\$ / \mathrm{kWh})$

$C^{V 2 X} \quad-$ Battery degradation penalty paid to the $\mathrm{EV}$ user for participating in $\mathrm{V} 2 \mathrm{G}$ services (\$/kWh)

$B_{v}^{\min }, B_{v}^{\max } \quad-$ Minimum and maximum possible state of charge (SOC) of $v^{\text {th }} \mathrm{EV}(\mathrm{kWh})$ respectively $x_{v}^{u b}, x_{v}^{l b} \quad-$ Maximum charging and discharging, i.e., vehicle to grid $(\mathrm{V} 2 \mathrm{G})$ power of $v^{\text {th }}$ $\mathrm{EV}(\mathrm{kW})$ respectively

$\eta_{v}^{c h}, \eta_{v}^{v 2 x} \quad-$ Efficiency of charging and discharging of the battery of $v^{\text {th }} \mathrm{EV}(\mathrm{kW})$ respectively.

EV-PV Power Converter Parameters (Index c):

$P_{c}^{\text {conv }} \quad-$ Rated power capacity of the DC/AC inverter $(\mathrm{kW})$

$P_{c}^{E V r} \quad-$ Rated power capacity of each EV charger in $c^{\text {th }} \mathrm{EV}-\mathrm{PV}$ power converter $(\mathrm{kW})$

$P_{c}^{P V r} \quad-$ Rated power of photovoltaic array (PV) connected to $c^{\text {th }}$ charger $\left(\mathrm{kW}_{\mathrm{p}}\right)$

$\eta_{c}^{\text {conv }} \quad-$ Rated efficiency of $c^{\text {th }}$ EV-PV charger (\%)

$K_{c}^{P V} \quad-\mathrm{PV}$ scaling factor that takes into account the losses due to orientation and shading with respect to a $1 \mathrm{~kW}$ optimally oriented PV array at car park $(\mathrm{kW})$

$N_{c}^{\text {conn }} \quad-$ Maximum number of EVs that can be connected to the $c^{\text {th }}$ EV-PV power converter 


\begin{tabular}{|c|c|}
\hline$c h$ & $\begin{array}{l}\text { - Maximum number of EVs that can be } \\
\text { simultaneously charged from } c^{\text {th }} \text { EV-PV } \\
\text { converter }\end{array}$ \\
\hline$K_{v, c}$ & $\begin{array}{l}\text { - Binary variable indicating connection of } \\
v^{\text {th }} \mathrm{EV} \text { with } c^{\text {th }} \text { charger }(1,0 \text {; Connected } \\
=1) \text {. }\end{array}$ \\
\hline \multicolumn{2}{|c|}{ V Forecast, Car Park and ISO Parameters (Index t): } \\
\hline & $\begin{array}{l}\text { - Time step for the model predictive con- } \\
\text { trol (h) }\end{array}$ \\
\hline & oer of EV in the car park at time $t$ \\
\hline & $\begin{array}{l}\text { - Number of EV-PV chargers in the car } \\
\text { park }\end{array}$ \\
\hline$P_{t}^{P V(f c)}$ & $\begin{array}{l}\text { - Power generation forecast of } 1 \mathrm{~kW}_{p} \mathrm{PV} \\
\text { array installed at the workplace or car } \\
\text { park }(\mathrm{kW})\end{array}$ \\
\hline$c$ & - Cost of obtaining PV energy $(\$ / \mathrm{kWh})$ \\
\hline & $\begin{array}{l}\text { - Maximum uncertainty in solar forecast } \\
\text { data }(\%)\end{array}$ \\
\hline$p_{t}^{e(b u y)}, p_{t}^{e(s e}$ & $\begin{array}{l}\text { - Market clearing price for buying and sell- } \\
\text { ing electricity from the grid respectively } \\
(\$ / \mathrm{kWh})\end{array}$ \\
\hline$p_{t}^{r(u p)}, p_{t}^{r(d n)}$ & $\begin{array}{l}\text { - Market clearing price for offering reserve } \\
\text { capacity for up and down regulation } \\
\text { respectively }(\$ / \mathrm{kW})\end{array}$ \\
\hline$P_{t}^{D N+}, P_{t}^{D N-}$ & $\begin{array}{l}\text { - Distribution network capacity for draw- } \\
\text { ing and feeding power to car park respec- }\end{array}$ \\
\hline
\end{tabular}

Optimization Variables (All Are Positive)

\begin{tabular}{|c|c|}
\hline & $-\mathrm{SOC}$ of $v^{t h} \mathrm{EV}$ battery at time $t(\mathrm{kWh})$ \\
\hline & $\begin{array}{l}\text { - Power generated by PV system connected } \\
\text { to the } c^{\text {th }} \text { charger at time } t(\mathrm{~kW})\end{array}$ \\
\hline$c^{c}$ & $\begin{array}{l}\text { - Binary variable that determines if the } v^{\text {th }} \\
\text { EV is active, i.e., charging/discharging at } \\
\text { a finite power or idle at time } t(1,0 \text {; Active } \\
=1)\end{array}$ \\
\hline & $\begin{array}{l}\text { - Binary variable that determines if the } v^{\text {th }} \\
\text { EV is in charge or V2G mode at time } t \\
(1,0 ; \text { Charge }=1)\end{array}$ \\
\hline & $\begin{array}{l}\text { - Binary variable that determines if the } c^{\text {th }} \\
\text { charger is drawing or feeding power to the } \\
\text { car park at time } t(1,0 \text {; Draw }=1)\end{array}$ \\
\hline${ }_{, v}^{(u p)}, x_{t, v}^{r(d n)}$ & $\begin{array}{l}\text { - Reserve power capacity offered to grid } \\
\text { for up and down regulation by } v^{\text {th }} \mathrm{EV} \text { at } \\
\text { time } t(\mathrm{~kW})\end{array}$ \\
\hline,$+ x_{t, v}^{e-}$ & $\begin{array}{l}\text { - Charging and discharging power of } v^{t h} \\
\text { EV at time } t \text { respectively }(\mathrm{kW})\end{array}$ \\
\hline$P_{t, c}^{\text {draw }}, P_{t, c}^{\text {feed }}$ & $\begin{array}{l}\text { - Power drawn and fed to car park by } c^{t h} \\
\text { EV-PV charger at time } t \text { respectively }(\mathrm{kW})\end{array}$ \\
\hline , $P$ & $\begin{array}{l}\text { - Power imported and exported to grid by } \\
\text { the EV car park at time } t \text { respectively }(\mathrm{kW}) \text {. }\end{array}$ \\
\hline
\end{tabular}

\section{INTRODUCTION}

$\mathbf{E}$ LECTRIC vehicles (EVs) provide a highly efficient mode of transportation with zero tail-pipe emission. The current estimate for the USA is that there will be 1.2 million EVs by 2020 [1]. Electric vehicles are, however, sustainable only

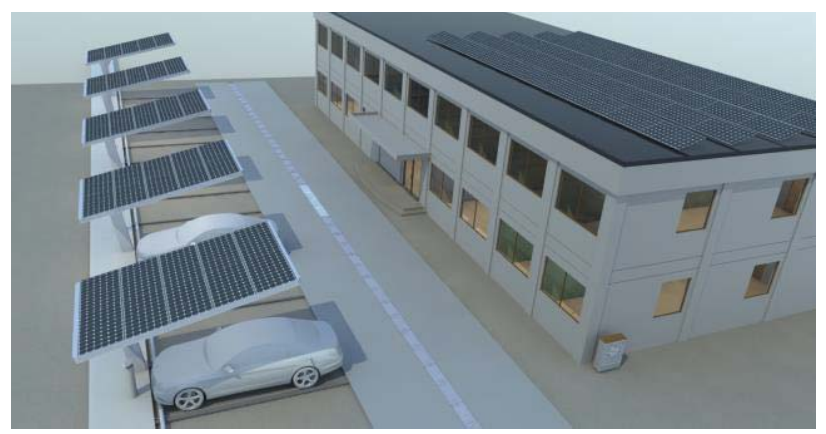

Fig. 1. EV charging powered by solar panels on roof and carport.

if the electricity used to charge them comes from sustainable sources. Electricity generated from a fuel mix that is largely dominated by fossil fuels does not eliminate the emissions but mostly moves it from the vehicle to the power plant [2], [3]. While this can have environmental advantages, complete elimination of emissions is contingent on utilizing non-emitting resources for electricity production. It is here that the phenomenal growth in the use of photovoltaic (PV) systems for distributed generation and its falling cost over the years can have a direct impact.

EVs used to commute to work are parked at the workplace for long hours during the day and it is generally the time when the sun is shining as well. Workplaces like industrial sites and office buildings harbor an excellent potential for PV panels with their large surfaces on flat roofs. This potential is largely unexploited today. Energy generated from PV arrays installed at the workplace and as solar carports can hence be used for charging EVs as shown in Fig. 1. This has several benefits:

1) EV battery doubles up as an energy storage for the PV.

2) The negative impact of large-scale PV and EV integration on distribution network is mutually reduced [4], [5].

3) Long parking time of EVs paves way for implementation of vehicle-to-grid (V2G) technology where the EV can offer energy and ancillary services to the grid [6]-[8].

4) Cost of EV charging from solar is cheaper than charging from the grid and net $\mathrm{CO}_{2}$ emission is zero [2], [9].

\section{A. Immediate, Average Rate and Randomly Delayed Charging}

Today, when an EV arrives at the workplace and is connected to the electric vehicle supply equipment (EVSE), the EV starts charging essentially immediately at the nominal maximum EVSE power rating, $P_{c}^{E V r}$. The charging continues at approximately constant power until the battery is nearly full. ${ }^{1}$ This is referred to as immediate charging (IMM) or uncontrolled charging [10]. This is the simplest form of charging requiring no information from the user or communication infrastructure and results in the lowest charging time. However, IMM typically results in a huge demand on the grid based on the EVSE, as shown in Fig. 2.

At the same time, the long parking times of EVs at workplace offers the flexibility in scheduling the charging in terms of both charging power and duration. This means that EVs can 


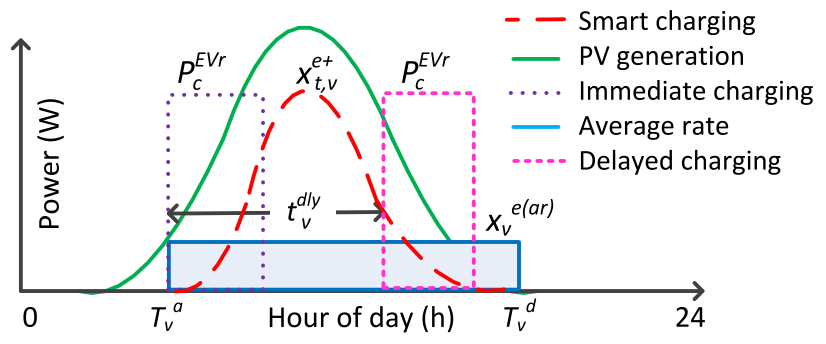

Fig. 2. Immediate, average rate, randomly delayed and smart charging of EV.

be charged at a much lower power than the EVSE nominal rating if the EV user arrival time, $T_{v}^{a}$, departure time, $T_{v}^{d}$ and required energy demand, $d_{v}$ are known. One approach is the "Average Rate" (AR) charging policy [10], where the charging power $x_{v}^{e(a r)}$ is the minimum of the EVSE capacity, $P_{c}^{E V r}$, and the ratio of the energy demand divided by the parking time of the $\mathrm{EV}^{1}$ :

$$
x_{v}^{e(a r)}=\operatorname{Min} \cdot\left\{\frac{d_{v}}{T_{v}^{d}-T_{v}^{a}}, P_{c}^{E V r}\right\} \quad \forall t \in\left\{T_{v}^{a}, T_{v}^{d}\right\}
$$

The advantage of the AR policy is that the charging of the fleet is spread throughout the day instead of being concentrated around the arrival time (typically early morning), as seen in Fig. 2. Combining the ideas of AR and IMM is Randomly Delayed Charging (RND): a type of charging where the start of the charging is delayed by a random time duration $t_{v} d l y$ such that the EV reaches its desired SOC by the departure time [11], [12]:

$$
t_{v}^{d l y}=\operatorname{Random}\left[0,\left(T_{v}^{d}-T_{v}^{a}\right)-\frac{d_{v}}{P_{c}^{E V r}}\right]
$$

Just like IMM, the charging power is fixed and equals the rated power of the EVSE, $P_{c}^{E V r}$. With a fleet of EV, the net charging profile of RND is similar to AR in the sense that the charging of different EV is spread-out in time throughout the day, instead of being concentrated at the arrival time.

At the same time, however, IMM, RND, and AR strategies are not completely 'smart' as the consumption has no correlation to the variation of local renewable generation, distribution network capacity constraints and/or energy prices.

\section{B. Smart Charging}

The optimal way to charge EVs is hence to schedule the charging by taking into consideration the EV user preferences, local renewable generation, distribution network and energy prices from the market. Fig. 2 shows an example of smart charging where the EV charging follows the PV generation. Further, EVs can have extremely fast ramp up and ramp down rates. Chademo and Combo EV charging standards for DC charging stipulate response time of $200 \mathrm{~ms}$ for power changes [13]. This makes EVs ideal candidates for providing

\footnotetext{
${ }^{1}$ The analysis does not consider the duration in the constant-voltage $(\mathrm{CV})$ charging mode, which occurs typically when EV battery is above $80 \%$ SOC and the maximum charging power is limited [42].
}

ancillary services in the form of regulation services to the grid [6], [7], [14], [15].

Following the formulation in [15] and [16], an Energy Services Company (ESCo) company acts as an intermediary between the wholesale market operated by the Independent System Operator (ISO) and the EV end-users. The ESCo operates at the workplace where employees drive to the office with an EV and the building has overhead PV installation or a solar carport. The motive of the ESCo is to schedule the charging of the EV and feeding of PV power to the grid in such a way that EV charging costs are lowered, regulation services are offered to the ISO and at the same time, the income from PV is increased. The ESCo achieves this motive by using an Energy Management System (EMS) to schedule the EV based charging on a multitude of inputs:

1) Information from the EV user about EV type, arrival and departure times, the state of charge (SOC) of EV battery, and energy demand.

2) Settlement point prices for buying and selling electricity from the grid at time $t\left(p_{t}^{e(b u y)}, p_{t}^{e(s e l l)}\right)$.

3) Clearing prices for capacity for offering reserves to the ISO for up and down regulation. $\left(p_{t}^{r(u p)}, p_{t}^{r(d n)}\right)$.

4) Distribution network limits for drawing and feeding power between the EV car park and the grid $\left(P_{t}^{D N+}\right.$, $\left.P_{t}^{D N-}\right)$. These values can be adjusted to implement demand side management (DSM).

5) Solar forecast information to help reduce the uncertainties due to variability in PV generation on diurnal and seasonal basis $\left(P_{t}^{P V(f c)}\right)$.

\section{Literature Review and Overview of Contributions}

Several earlier works have formulated the optimization problem to charge EV based on renewable generation, energy prices, and offer of ancillary services.

Fuzzy logic is used to optimize the EV charging based on PV generation forecast and energy prices in [17]; and on V2G frequency regulation and grid energy exchange in [18]. The disadvantage is that the use of fuzzy logic without optimization techniques does not guarantee that the obtained solution is optimal.

In [15] and [16], linear programming (LP) is used to find the optimal EV strategy for charging and offering reserves based on market prices. In [19], LP is used to reduce the cost of charging EV from PV based on time of use tariffs and PV forecasting. Cost reduction of $6 \%$ and $15.2 \%$ compared to the base case are obtained for simulation for $12 \mathrm{EV}$ powered from a 50kW PV system. The LP formulation in [20] and heuristic methods used in [21] aim to achieve the two goals: increasing the PV self-consumption in a micro-grid by charging of EVs and reducing the dependency on the grid. However, there is no consideration for time of use tariffs without which there is no incentive to achieve the two goals. In [22], LP is used for planning the EV charging based on renewable power forecasting, spinning reserve and $\mathrm{EV}$ user requirements in a micro-grid. A two-layered optimization is used for EV charging based on variable energy prices which results in increased number of EVs charged and up to $18 \%$ increased 
revenues [23]. While realistic vehicular mobility patterns are used, there is, however, no consideration for $\mathrm{V} 2 \mathrm{G}$, regulation, or local generation. A MILP formulation in [24] and [25] is used for EV charging based on PV, EV user, energy prices, and without the offer of regulation services. $10 \%-171 \%$ reduction in net costs are obtained in [24] based on the proposed method.

Stochastic programming (SP) is used in [26] to plan EV charging and offer regulation services based on day-ahead and intraday market prices. For a case study with $50 \mathrm{EV}$, cost reduction of $1 \%$ to $15 \%$ was achieved. A two-stage SP is proposed in [27] for workplace charging of EV based on PV, V2G and dynamic energy prices resulting in $7.2 \%$ and $6.9 \%$ average cost reduction.

With respect to ancillary services, a dynamic control of EVs in [28], robust optimization in [29], and SP based on Markov decision problem in [30], are used to provide frequency regulation services while considering the EV user requirements and regulation prices.

Earlier works have considered the different applications of smart charging as separate optimization problems or as a combination of two or three applications. The disadvantage is that each application gives a different optimized EV charging profile and all these profiles cannot be implemented on the same EV at the same time. A better approach is to combine them into one formulation, which will then yield a single optimized EV charging profile. The second disadvantage is that the above formulations do not consider the characteristics of the EV charging hardware. This is vital as the hardware is more expensive than the smart charging controller and its algorithms.

The main contributions of the work reported below include:

- Proposing an integrated model that captures charging of EV from PV, use of dynamic grid prices, implementation of V2G for grid support, using EV to offer ancillary services, and considering distribution network capacity constraints as a single mixed integer linear programming (MILP) formulation. The paper demonstrates that the integrated formulation results in large cost savings that are much higher than what has been achieved earlier. This is due to the addition of benefits from each application, such that the net benefit is economically attractive. With the prior approaches, the economic benefits were too small to warrant mass adoption of smart charging.

- The paper proposes the use of an integrated EV-PV converter for the combined optimization of EV charging and PV generation. This provides higher efficiency due to the direct current (DC) power exchange between EV and PV; leads to a lower capital cost of the power converter as it needs only a single DC/AC inverter to the grid; and removes the necessity for communication between $\mathrm{EV}$ charger and PV inverter as they are now integrated.

- The paper shows that the benefit of $V 2 G$ from energy sales can be far outweighed by the increased upregulation that can be offered by a bidirectional EV charger when battery degradation costs are included in the optimization.
- With a large number of EV parked at the workplace with long parking times, multiplexing a few EVSEs to a larger number of EVs is a cost-effective strategy [31]-[33]. The scheduling of the multiplexing is formulated in the MILP to reduce charging infrastructure cost.

\section{Structure of the Paper}

Section II describes the layout and parameters of the EMS and the EV-PV car park infrastructure. In Section III, the MILP formulation of the EMS is explained and the parameters, constraints and objective function are elaborated. Section IV uses PV generation and market data for Austin, TX to estimate the optimized net cost of charging an EV fleet from PV. The costs are compared to immediate and average rate charging policies to evaluate the cost reduction. Last part of the section delves into implementation aspects of the optimization: adaptability, capital cost and scalability.

\section{Preliminaries AND InPuts}

\section{A. Layout of the EMS}

The schematic of the EV-PV charger and the EMS used by the ESCo to optimize the EV charging is shown in Fig. 3.

1) EV and User Input: Each EV arrives at the car park with a state of charge $B_{v}^{a}$ at time $T_{v}^{a}$ and is parked at one of the several EV-PV chargers. The EV owners provide the information to the EMS about their expected departure time $T_{v}^{d}$ and charging energy demand $d_{v}$. This means that the departure SOC of the vehicle $B_{v}^{d}$ is:

$$
B_{v}^{d}=B_{v}^{a}+d_{v}
$$

If the required SOC is not reached by the departure time, the EV owner will be compensated by the ESCo at the rate of $C_{v}^{p} \$ / \mathrm{kWh}$. The users can enter the maximum and minimum allowed SOC of the EV $\left(B_{v}^{\min }, B_{v}^{\max }\right)$ and the maximum charging and discharging power $\left(x_{v}^{u b}, x_{v}^{l b}\right)$ respectively. By setting $x_{v}^{l b}$ to a non-zero value, the users can choose to participate in V2G services. The efficiency of the EV battery for charging and discharging $\left(\eta_{v}^{c h}, \eta_{v}^{v 2 x}\right)$ is either obtained from the EV or stored in a database within the EMS for different EV models.

2) EV-PV Charger: The 'EV-PV charger' as the term is used here means an integrated power converter that consists of three ports to connect to the EVs, PV, and the AC grid, as shown in Fig. 3 [31], [34], [35]. Each EV-PV charger is connected to a PV array of rated power $P_{c}^{P V r}$ via a maximum power point tracking (MPPT) DC/DC converter [36]. The output of the DC/DC PV converter is connected to an internal DC-link. The DC-link is connected to the grid via a DC/AC inverter of rated power $P_{c}^{c o n v}$, such that $P_{c}^{P V r} \leq P_{c}^{c o n v}$. There are $N_{c}^{c h}$ number of isolated DC/DC converters for EV charging that are connected to the DC-link and each have a rated power $P_{c}^{E V r}$. All power exchanges between any of the three ports namely PV, EV, and grid are via the DC-link.

This integrated converter provides several benefits compared to using separate converters for PV and EV connected over the $50 \mathrm{~Hz}$ AC grid. First, direct interconnection of the $\mathrm{PV}$ and EV over a DC-link is more efficient than an AC 


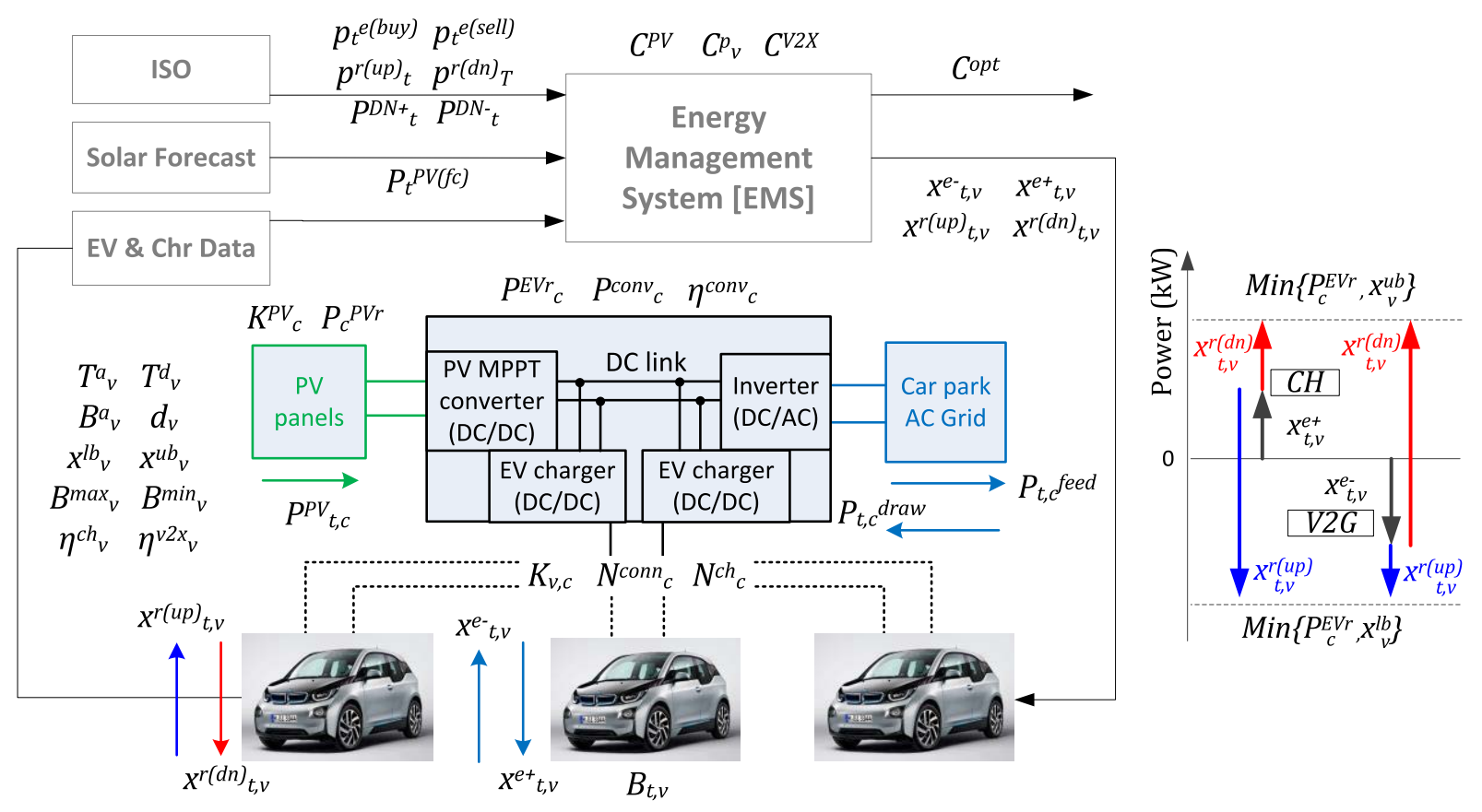

Fig. 3. (Left) Schematic of the Energy Management System for the solar powered EV parking garage. $N_{c}^{c h}$ of the total $N_{c}^{c o n n}$ EV connected to each EV-PV charger can be simultaneously charged or discharged, where $N_{c}^{c h} \leq N_{c}^{c o n n}$ (Right) offer of reserve power capacity $x_{t, v}^{r(u p)}, x_{t, v}^{r(d n)}$ for up and down regulation during charging $(\mathrm{CH})$ and discharging $(\mathrm{V} 2 \mathrm{G})$ of EV.

interconnection [37], [38]. Second, the integrated converter requires one common inverter to the $\mathrm{AC}$ grid instead of separate inverters for PV and EV. This reduces the component count and size of the converter [31]. Third, by making the isolated DC/DC converter for the EV bidirectional, the EV can now offer V2G services via the integrated converter.

Due to the long parking times of EVs at the workplace, it is economical to use a single EVSE that can be multiplexed to several EVs, with the possibility to charge the EVs simultaneously or sequentially as shown in Fig. 3 [31]-[33]. Therefore, $N_{c}^{c o n n}$ EVs can be connected to each EV-PV charger via DC isolators. The binary variable $K_{v, c}=1$ indicates the physical connection of $v^{\text {th }}$ EV with $c^{\text {th }}$ charger and a zero value indicates otherwise.

Each EV-PV charger has $N_{c}^{c h}$ number of isolated DC/DC converters, where $N_{c}^{c h} \leq N_{c}^{c o n n}$. As per the EV charging standards [39], each EV must be connected to separate power converter and isolated from all power sources. This means that $N_{c}^{c h}$ of the total $N_{c}^{c o n n}$ EVs connected to each EV-PV charger can be simultaneously charged or discharged. In the simple case where $N_{c}^{c h}=1, N_{c}^{c o n n}=2$ and $P_{c}^{c o n v}=P_{c}^{E V r}$, two EVs are connected to one EV-PV charger and one of the two can (dis)charge at any time up to a power of $P_{c}^{c o n v}$. The binary variable $a_{t, v}^{c}$ indicates which of the $N_{c}^{c o n n}$ EVs connected to an EV-PV charger is actively (dis)charging at time $t$.

$$
\begin{gathered}
\sum_{v=1}^{v=V} K_{v, c} \leq N_{c}^{c o n n} \quad \forall c \\
\sum_{v=1}^{v=V} K_{v, c} a_{t, v}^{c} \leq N_{c}^{c h} \quad \forall c
\end{gathered}
$$

Each EV-PV charger feeds $P_{t, c}^{\text {feed }}$ or draws $P_{t, c}^{\text {draw }}$ power from the EV car park as determined by the EMS. Different EV-PV chargers can exchange power within the car park and these are 'intra-park' power exchanges. When the net 'intra-park' energy exchanges are non-zero, the EV park imports or exports power with the external grid referred to as $P_{t}^{g(i m p)}, P_{t}^{g(\exp )}$ respectively.

\section{B. Trading Energy and Reserves in the Energy Market}

The ESCo uses the EMS to control the solar-powered EV car park for energy trading with the grid. Since $P_{t}^{g(i m p)}, P_{t}^{g(\exp )}$ are small relative to the power traded in the market, the ESCo is a price taker and does not influence the market clearing prices. It uses the settlement point prices for trading power in the market and reserve capacity prices for offering up and down regulation services. Markets like the Electric Reliability Council of Texas (ERCOT) provide different prices for offering capacity reserves for up and down regulation (asymmetric, $p_{t}^{r(u p)} \neq p_{t}^{r(d n)}$ ). However, other U.S. markets such as PJM trade up and down regulation as a single product (symmetric). In order to make the EMS flexible and work with both types of markets, it is designed to take different inputs for $p_{t}^{r(u p)}$ and $p_{t}^{r(d n)}$ and allow for a requirement that up and down regulation quantities could be equal.

The amount of reserves offered by the EV depends on whether the user enables V2G option or not, i.e., if $x_{v}^{l b}=0$ or not. When an EV is connected to a bidirectional charger and $x_{v}^{l b} \neq 0$, even an idle EV that is not charging can offer up and down regulation up to $x_{v}^{l b}$ and $x_{v}^{u b}$ respectively. With a unidirectional charger, an idle EV that is not charging can only offer down regulation up to $x_{v}^{u b}$. 
Power generated by PV panels can be ramped down by moving out of the maximum power point of the PV array. This can be achieved by controlling the DC/DC converter in the EV-PV charger that is connected to the PV array. This PV power curtailment can also be offered for down-regulation services.

\section{Receding Horizon Model Predictive Control}

There are two sources of variability in the EV-PV system. The first is the diurnal and seasonal variation in PV generation due to changes in weather. The EMS uses solar forecast information as an input to predict the PV variation. Any solar forecast data source can be used for the given MILP formulation. For example: the online short-term solar power forecasting [40], the autoregressive integrated moving average (ARIMA) models or any of the methods listed in [41]. $P_{t}^{P V(f c)}$ is power generation forecast for an optimally orientated $1 \mathrm{~kW}_{p} \mathrm{PV}$ array at the car park location with a maximum uncertainty in forecast of $y_{P V}^{f c}$. It is vital to recognize that all forecasting methods will have forecasting errors in terms of temporal and spatial resolution. The second variability is the variation in the arrival and departure patterns of the EV user and the EV parameters like charging powers limits, efficiency of the battery and SOC.

The EMS is implemented as a receding horizon model predictive control with a time step $\Delta T$ to manage these two variations. The horizon for the model is from 00:00AM to 23:59 PM at midnight. This means that at every time step, the EMS can utilize updated forecast information and input parameters, perform the optimization and plan the EV charging for the rest of the day. Hence, the receding horizon implementation helps in minimizing forecasting errors and model inaccuracies at every time step.

\section{MILP FORMULATION}

This section describes the objective function and constraints for the MILP formulation of the EMS. It is important to note that all optimization variables considered are positive.

\section{A. Acceptance Criteria}

When an EV arrives at the EV car park, it is connected to one of the $C$ number of EV-PV chargers. As mentioned earlier, each EV-PV charger can have up to $N_{c}^{c o n n}$ number of EV connected to it. The user links to the EMS and the EMS instructs the user on which EV-PV charger he/she must connect to, based on two 'acceptance criteria'. The first criteria is that the energy demand $d_{v}$ and parking time, $\left(T_{v}^{d}-T_{v}^{a}\right)$ of all the EVs connected to one EV-PV charger must be within the power limits of the charger, (6). The second criteria is that the arrival SOC of the vehicle must be above the minimum SOC as set by the user, (7). This is to ensure that constraint (21) is satisfied.

$$
\begin{aligned}
\sum_{v=1}^{V} \sum_{c=1}^{C} K_{v, c} \frac{d_{v}}{T_{v}^{d}-T_{v}^{a}} & \leq \operatorname{Min} \cdot\left\{N_{c}^{c h} P_{c}^{E V r}, P_{c}^{c o n v}\right\} \quad \forall v, c \\
B_{v}^{\text {min }} & \leq B_{v}^{a} \quad \forall v
\end{aligned}
$$

\section{B. Constraints: EV and User Inputs}

The EMS controls the charging power $x_{t, v}^{e+}$ and discharging power $x_{t, v}^{e-}$, up and down regulation reserve capacity $x_{t, v}^{r(u p)}, x_{t, v}^{r(d n)}$ of each EV and the power extracted from the PV system $P_{t, c}^{P V}$ of each charger at time $t$. Equations (8) and (9) are used to set the charging power of the EV to zero before the arrival $\left(t<T_{v}^{a}\right)$ and after the departure of the $\operatorname{EV}\left(t \geq T_{v}^{d}\right)$.

The binary variable $a_{t, v}^{c}$ indicates if the EV is connected to the isolated DC/DC converter for charging/discharging and can offer regulation services or not. Since an EV cannot simultaneously charge and discharge, a second binary variable $a_{t, v}^{c h_{2} v 2 x}$ is used to ensure that only one of the two variables $x_{t, v}^{e-}, x_{t, v}^{e+}$ has a non-zero value for a given $t . a_{t, v}^{c h} v^{2 x}$ is set to 1 for charging and to 0 for V2G. $x_{t, v}^{e-}, x_{t, v}^{e+}$ have to be within the power limits of the power converter $P_{c}^{E V r}$ and the charging and discharging power limits $x_{v}^{u b}, x_{v}^{l b}$ as set by the EV, respectively, as shown in equations (10)-(15).

The maximum charging and discharging powers are also dependent on the SOC of the EV battery as shown in (16) and (17). For example, fast charging of EV battery cannot be done beyond $80 \%$ SOC of the battery [42]. Here, it is assumed that the maximum charging power linearly reduces from $x_{v}^{u b}$ to zero when the battery is charged beyond $80 \%$ SOC till $100 \%\left(S_{c h}=0.8\right)$. Similarly the maximum discharging power reduces linearly from $x_{v}^{l b}$ to zero when the battery is discharged below $10 \%$ SOC till $0 \%\left(S_{v 2 x}=0.1\right)$. Even though the exact dependence of battery power on the SOC is non-linear, this is not considered here as it is beyond the scope of the paper and would prevent us from casting the problem into an MILP formulation.

$$
\begin{aligned}
& x_{t, v}^{e-}, x_{t, v}^{e+}, x_{t, v}^{r(u p)}, x_{t, v}^{r(d n)}, a_{t, v}^{c}=0 \quad \forall t<T_{v}^{a} \\
& x_{t, v}^{e-}, x_{t, v}^{e+}, x_{t, v}^{r(u p)}, x_{t, v}^{r(d n)}, a_{t, v}^{c}=0 \quad \forall t \geq T_{v}^{d} \\
& x_{t, v}^{e+} \leq x_{v}^{u b}\left(a_{t, v}^{c}\right) \quad \forall t, v \\
& x_{t, v}^{e+} \leq x_{v}^{u b}\left(a_{t, v}^{c h-v 2 x}\right) \quad \forall t, v \\
& x_{t, v}^{e-} \leq-x_{v}^{l b}\left(a_{t, v}^{c}\right) \quad \forall t, v \\
& x_{t, v}^{e-} \leq-x_{v}^{l b}\left(1-a_{t, v}^{c h-v 2 x}\right) \quad \forall t, v \\
& x_{t, v}^{e-}, x_{t, v}^{e+} \leq P_{c}^{E V r} \quad \forall K_{v, c}=1 \\
& a_{t, v}^{c}, a_{t, v}^{c h \_v 2 x}, a_{t, c}^{d_{f} f} \in\{0,1\} \quad \forall t, c, v \\
& x_{t, v}^{e+} \leq \frac{-x_{v}^{u b}}{\left(1-S_{c h}\right)}\left(\frac{B_{t, v}}{B_{v}^{\max }}-1\right) \quad \forall t, v \\
& x_{t, v}^{e-} \leq \frac{-x_{v}^{l b}}{S_{v 2 x}}\left(\frac{B_{t, v}}{B_{v}^{\max }}\right) \quad \forall t, v
\end{aligned}
$$

Equations (18)-(23) are used to set the initial SOC of the EV battery and estimate the SOC of the battery $B_{t, v}$ based on the charging and discharging efficiency $\left(\eta_{v}^{c h}, \eta_{v}^{v 2 x}\right)$ and power $\left(x_{t, v}^{e+}, x_{t, v}^{e-}\right)$ respectively. At every time step of the receding horizon, the current time and SOC of all EVs are updated into the parameters $B_{v}^{a}$ and $T_{v}^{a}$. The EMS restricts the SOC to be within the limits $B_{v}^{\min }, B_{v}^{\max }$ as set by the EV and/or user. It is assumed that the net energy delivered/absorbed by the EV over one time period due to offer of reserves is zero [15], [16]. 
Hence, $x_{t, v}^{r(u p)}, x_{t, v}^{r(d n)}$ do not appear in (23) for SOC estimation.

$$
\begin{aligned}
& B_{t, v}=0 \quad \forall t<T_{v}^{a} \\
& B_{t, v}=B_{v}^{a} \quad \forall t=T_{v}^{a} \\
& B_{t, v} \leq d_{v}+B_{v}^{a} \quad \forall t=T_{v}^{d} \\
& B_{t, v} \geq B_{v}^{\min } \quad \forall \mathrm{t} \geq T_{v}^{a} \\
& B_{t, v} \leq B_{v}^{\max } \quad \forall \mathrm{t} \geq T_{v}^{a} \\
& B_{t+1, v}=B_{t, v}+\Delta T\left(x_{t, v}^{e+} \eta_{v}^{c h}-\frac{x_{t, v}^{e-}}{\eta_{v}^{v 2 x}}\right) \quad \forall t, v .
\end{aligned}
$$

\section{Constraints: EV-PV Charger and Car Park}

Under normal operation, the EMS extracts maximum power from the PV array using MPPT as shown in right side of equation (24). The PV power is dependent on the scaling factor $K_{c}^{P V}$ which scales the installation characteristics (e.g., azimuth, tilt, module parameters) of the PV array connected to the charger $c$ with respect to the $1 \mathrm{kWp}$ reference array used for the forecast data $P_{t}^{P V(f c)}$. The EMS implements PV curtailment if it is uneconomical to draw PV power or if there are distribution network constraints for feeding to the grid. This means that the actual PV power extracted $P_{t, c}^{P V}$ can be lower than the MPPT power of the array, as shown in (24).

The DC-link is used for power exchanges between the three ports of the converter and (25) is the power balance equation for the EV-PV converter. It is assumed that each of the power converters within the EV-PV charger operates with an efficiency $\eta_{c}^{c o n v}$. Power levels $P_{t, c}^{\text {draw }}, P_{t, c}^{\text {feed }}$ are limited by the power limit of the inverter port $P_{c}^{\text {conv }}$. The binary variable $a_{t, c}^{d f f}$ is used to ensure that only one of the two variables has a non-zero value for a given $t$ as shown in (26)-(27).

$$
\begin{aligned}
& P_{t, c}^{P V} \leq K_{c}^{P V} P_{c}^{P V r} P_{t}^{P V(f c)} \quad \forall t, c \\
& \left\{P_{t, c}^{P V}+P_{t, c}^{\text {draw }}+\sum_{v=1}^{v=V}\left(K_{v, c} x_{t, v}^{e-}\right)\right\} \eta_{c}^{\text {conv }} \\
& =\left\{P_{t, c}^{\text {feed }}+\sum_{v=1}^{v=V}\left(K_{v, c} x_{t, v}^{e+}\right)\right\} / \eta_{c}^{c o n v} \quad \forall t, c, v \\
& P_{t, c}^{\text {draw }} \leq P_{c}^{\text {conv }}\left(a_{t, c}^{d_{-} f}\right) \quad \forall t, c \\
& P_{t, c}^{\text {feed }} \leq P_{c}^{\text {conv }}\left(1-a_{t, c}^{d_{f} f}\right) \quad \forall t, c
\end{aligned}
$$

The intra car-park power exchanges between different EV-PV chargers are related to the power exchanged with the external grid $P_{t}^{g(i m p)}, P_{t}^{g(\exp )}$ using (28). Both $P_{t}^{g(i m p)}, P_{t}^{g(\exp )}$ will not be non-zero at the same time because of the way the objective function is formulated and because $p_{t}^{e(b u y)} \geq p_{t}^{e(s e l l)}$ at all times. $P_{t}^{g(i m p)}, P_{t}^{g(\exp )}$ should be within the distribution network capacity $P_{t}^{D N+}, P_{t}^{D N-}$ as shown in (29)-(30). $P_{t}^{D N+}$, $P_{t}^{D N-}$ are used as a thermal proxy for all potential limitations in the distribution network including voltage limits, line limits, and transformer capacity. The values can come from the distribution system operator (DSO), ISO or ESco based on loading and voltage in the network and can be set at every time step in the receding horizon implementation.

$$
\begin{aligned}
\sum_{c=1}^{c=C}\left(P_{t, c}^{\text {draw }}-P_{t, c}^{\text {feed }}\right) & =P_{t}^{g(\text { imp })}-P_{t}^{g(\text { exp })} \quad \forall t \\
P_{t}^{g(i m p)} & \leq P_{t}^{D N+} \quad \forall t \\
P_{t}^{g(\text { exp })} & \leq P_{t}^{D N-} \quad \forall t
\end{aligned}
$$

Finally, the up and down regulation offered $x_{t, v}^{r(u p)}, x_{t, v}^{r(d n)}$ should be within the power limitations of the EV $\left(x_{v}^{u b}, x_{v}^{l b}\right)$ and the EV charger port $P_{c}^{E V r}$ as shown in Fig. 3. From the EV-PV charger perspective, the regulation power offered must be within the power rating of the inverter port $P_{c}^{c o n v}$, the power exchanged with the grid $P_{t, c}^{\text {draw }}, P_{t, c}^{\text {feed }}$ and the SOC of the EV battery (like (16), (17)). This is summarized in equations (31)-(36). While asymmetric reserve offers are assumed here $\left(x_{t, v}^{r(u p)} \neq x_{t, v}^{r(d n)}\right)$, symmetric reserves can be achieved by including $x_{t, v}^{r(u p)}=x_{t, v}^{r(d n)}$ in the constraints.

$$
\begin{aligned}
& \sum_{v=1}^{v=V} K_{v, c} x_{t, v}^{r(u p)}+P_{t, c}^{f e e d} \leq P_{c}^{c o n v} \quad \forall t, c, v \\
& \sum_{v=1}^{v=V} K_{v, c} x_{t, v}^{r(d n)}+P_{t, c}^{d r a w} \leq P_{c}^{c o n v} \quad \forall t, c, v \\
& x_{t, v}^{e-}+x_{t, v}^{r(u p)} \leq P_{c}^{E V r}\left(a_{t, v}^{c}\right) \quad \forall K_{v, c}=1 \\
& \left(x_{t, v}^{e-}-x_{t, v}^{e+}\right)+x_{t, v}^{r(u p)} \leq\left(-x_{v}^{l b}\right) \quad \forall t, v \\
& x_{t, v}^{e+}+x_{t, v}^{r(d n)} \leq P_{c}^{E V r}\left(a_{t, v}^{c}\right) \quad \forall K_{v, c}=1 \\
& \left(x_{t, v}^{e+}-x_{t, v}^{e-}\right)+x_{t, v}^{r(d n)} \leq x_{v}^{u b} \quad \forall t, v \\
& \left(x_{t, v}^{e+}-x_{t, v}^{e-}\right)+x_{t, v}^{r(d n)} \leq \frac{-x_{v}^{u b}}{\left(1-S_{c h}\right)}\left(\frac{B_{t, v}}{B_{v}^{\max }}-1\right) \forall t, v \\
& \left(x_{t, v}^{e-}-x_{t, v}^{e+}\right)+x_{t, v}^{r(u p)} \leq \frac{-x_{v}^{l b}}{S_{v 2 x}}\left(\frac{B_{t, v}}{B_{v}^{\max }}\right) \quad \forall t, v .
\end{aligned}
$$

\section{Objective Function}

$$
\begin{aligned}
& \text { Min. } C^{o p t}=\left(B_{v}^{a}+d_{v}-B_{T_{v}^{d}, v}\right) C_{v}^{p} \\
& +\triangle T \sum_{t=1}^{T}\left(P_{t}^{g(\text { imp })} p_{t}^{e(b u y)}-P_{t}^{g(e x p)} p_{t}^{e(s e l l)}\right) \\
& -\triangle T\left(1-y_{P V}^{f c}\right)\left(\eta_{c}^{c o n v}\right)^{2} \\
& \times \sum_{t=1}^{T} \sum_{c=1}^{C} \sum_{v=1}^{V} K_{v, c}\left\{x_{t, v}^{r(u p)} p_{t}^{r(u p)}+x_{t, v}^{r(d n)} p_{t}^{r(d n)}\right\} \\
& +\triangle T \sum_{t=1}^{T} \sum_{v=1}^{V} x_{t, v}^{e-} C^{V 2 X}+\triangle T \sum_{t=1}^{T} \sum_{c=1}^{C} P_{c}^{P V r} P_{t}^{P V(f c)} C^{P V}
\end{aligned}
$$

The objective function is to minimize the total net costs $C^{o p t}$ of EV charging, feeding PV power, and offering reserves. The formulation is such that the $C^{\text {opt }}$ can be positive or negative. It has five components, namely:

- The penalty to be paid to the user if the energy demand $d_{v}$ is not met by the departure time $T_{v}^{d}$. $C_{v}^{p}$ is EV user specific and the penalty can be different for each user based on EV battery size, tariff policy and customer 'loyalty' program. 
- The cost of buying and selling energy from the grid based on the settlement point prices $p_{t}^{e(b u y)}, p_{t}^{e(s e l l)}$. The market dynamics will ensure that $p_{t}^{e(b u y)} \geq p_{t}^{e(\text { sell })}$.

- Income $S^{a s}$ obtained from offering reserve capacity $x_{t, v}^{r(u p)}, x_{t, v}^{r(d n)}$ to the ISO. $\left(\eta_{c}^{\text {conv }}\right)^{2}$ indicates the energy losses in the two step conversion between the EV and grid port of the EV-PV charger. Since the reserves offered to the grid have to be guaranteed and the uncertainty in the PV forecast is $y_{P V}^{f c}$, only a fraction $\left(1-y_{P V}^{f_{c}}\right)$ of the available reserves are guaranteed and sold to the ISO.

- EV battery capacity degrades due to the additional cycles caused by the V2G operation and EV user is compensated for this loss. Typical value of $C^{V 2 X}=4.2 \not / \mathrm{kWh}$ based on analysis in [43] and [44]. The battery degradation due to variable power smart charging is not considered as several studies have shown that its effect is insignificant [45]-[47].

- PV power that is used to charge the EV need not always be free of cost. If the PV is installed by a third-party, it can be obtained at a pre-determined contractual cost of $C^{P V}$.

\section{E. MILP Implementation}

The EMS engine is implemented in C\# leveraging Microsoft Solver Foundation for algebraic modeling in Optimization Modeling Language (OML). MS SQL Server database is used to warehouse system inputs, namely the EV, charger, network and market data as well as the decision outputs that are sent to the EV-PV chargers in the field. The MILP formulation is solved using branch-and-bound (B\&B) algorithm using 'LPsolve' open source solver. One of the main advantages of the $\mathrm{B} \& \mathrm{~B}$ algorithm is that, given enough computation time, it guarantees global optimality despite the non-convex nature of the problem. The EV-PV chargers will be interfaced with the output database to implement the optimal power profiles.

\section{Simulation Results}

Simulations are performed to test the validity of the proposed MILP formulation and to quantify the reduction in costs of EV charging from PV with respect to AR and IMM.

\section{A. Simulation Parameters}

Settlement point prices (SPP) and prices for reserve capacity (REGUP, REGDN) are obtained from the ERCOT dayahead market (DAM) for Austin, Texas for 2014 for load zone LZ_AEN, as shown in Fig. 4. These are wholesale energy prices with a data resolution of $1 \mathrm{hr}$. Since separate values for $p_{t}^{e(s e l l)}$ was not available, it is assumed that $p_{t}^{e(s e l l)}=0.98 * p_{t}^{e(b u y)}$.

For 2014 , the largest values observed for $p_{t}^{e(b u y)}, p_{t}^{r(u p)}$, $p_{t}^{r(d n)}$ were $136.47 \phi / \mathrm{kWh}, 499.9 \phi / \mathrm{kWh}$ and $31 \phi / \mathrm{kWh}$ respectively while the average values were $3.9 \phi / \mathrm{kWh}, 1.25 \phi / \mathrm{kWh}$, $0.973 \not / \mathrm{kWh}$. It can be clearly seen than energy prices are normally much higher than regulation prices, but there are several instances where it is otherwise.

The PV generation data is obtained from the Pecan Street Project database for a house in the Mueller neighborhood with

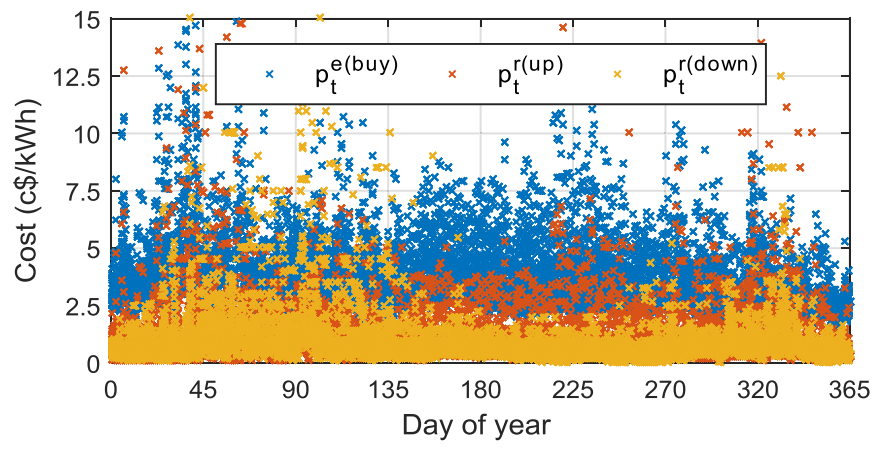

Fig. 4. Settlement point and regulation prices from ERCOT for 2014. Values greater than $15 \mathrm{c} / \mathrm{kWh}$ are not shown to maintain scale.

TABLE I

EV AND EV-PV CHARGER DATA

\begin{tabular}{|c|c|c|c|c|c|c|c|}
\hline \hline $\mathbf{v}$ & $\boldsymbol{T}_{\boldsymbol{v}}^{\boldsymbol{a}}$ & $\boldsymbol{T}_{\boldsymbol{v}}^{\boldsymbol{d}}$ & $\mathbf{d}$ & $\boldsymbol{B}_{\boldsymbol{v}}^{\boldsymbol{a}}$ & $\boldsymbol{B}_{\boldsymbol{v}}^{\max }$ & $\begin{array}{c}\text { Chr } \\
\text { conn. }\end{array}$ & $\begin{array}{c}\boldsymbol{P}_{\boldsymbol{c}}^{\text {EV r }} \\
\boldsymbol{P}_{\boldsymbol{c}}^{\boldsymbol{c o n v}}\end{array}$ \\
\hline \multicolumn{6}{|c|}{$(\mathrm{h})$} & \multicolumn{5}{|c|}{$(\mathrm{kWh})$} & & & $(\mathrm{kW})$ \\
\hline 1 & 900 & 1700 & 40 & 20 & 85 & 1 & 10 \\
\hline 2 & 830 & 1630 & 30 & 20 & 60 & 1 & 10 \\
\hline 3 & 930 & 1730 & 10 & 5 & 24 & 2 & 10 \\
\hline 4 & 900 & 1700 & 40 & 20 & 85 & 3 & 10 \\
\hline 5 & 830 & 1630 & 30 & 20 & 60 & 4 & 10 \\
\hline 6 & 930 & 1730 & 10 & 5 & 24 & 4 & 10 \\
\hline
\end{tabular}

a $11.1 \mathrm{~kW}$ PV system [48]. The data resolution is $1 \mathrm{~min}$. The power output is scaled down for a $1 \mathrm{~kW}$ system for use as $P_{t}^{P V(f c)}$ with $y^{P V(f c)}=10 \%$. It is assumed that the PV installation at the car park is owned by the workplace and hence $C^{P V}=0$.

The EV arrival and departure times and SOC requirements are listed in Table I for 6 EVs. The EV data imitates the capacity of a Tesla Model S, BMW i3 and a Nissan Leaf. For all the EVs, $B_{v}^{\min }=5 \mathrm{kWh}, x_{v}^{u b}=50 \mathrm{~kW}, x_{v}^{l b}=(-10 \mathrm{~kW})$, $\eta_{v}^{c h}=\eta_{v}^{v 2 x}=0.95, C_{v}^{p}=1 \$ / \mathrm{kWh}, C^{V 2 X}=4.2 \not / \mathrm{kWh}$. The penalty $C_{v}^{p}$ is approximately 25 times the average wholesale ERCOT electricity price of $3.9 \phi / \mathrm{kWh}$.

There are 4 EV-PV chargers and Table I shows the connections of the $6 \mathrm{EVs}$ to the 4 chargers in 'Chr conn.'. $10 \mathrm{~kW}_{p} \mathrm{PV}$ is connected to each of chargers $1,2,4$ and no $\mathrm{PV}$ is connected to charger 3. Chargers 1,4 have two EV connected to them. $N_{c}^{c h}=1$ for all chargers, which means that only one of the two EVs can be charged at a time for chargers 1,4. The following parameters are used: $\eta_{c}^{c o n v}=0.96, P_{c}^{E V r}=P_{c}^{c o n v}=10 \mathrm{~kW}$, $P_{t}^{D N+}=P_{t}^{D N-}=40 \mathrm{~kW} . \Delta T=15 \mathrm{~min}$ for all simulation.

\section{B. Simulation Results}

1) Average Rate, Randomly Delayed and Immediate Charging: The net costs of EV charging and PV sales for average rate $C^{a r}$, randomly delayed $C^{\text {rnd }}$ and immediate charging $C^{i m m}$ are estimated using (1), (2), (40).

$$
\begin{aligned}
C^{a r}, & C^{r n d}, C^{i m m}=C^{e v}-S^{P V} \\
& =\Delta T \sum_{t=1}^{T} \sum_{v=1}^{v=V} x_{t, v}^{e+} p_{t}^{e(b u y)} /\left(\eta_{c}^{\text {conv }}\right)^{2} \\
& -\triangle T \sum_{t=1}^{T} \sum_{c=1}^{C}\left(\eta_{c}^{c o n v}\right)^{2} P_{c}^{P V r} P_{c}^{P V(f c)}\left(p_{t}^{e(s e l l)}-C^{P V}\right)
\end{aligned}
$$


TABLE II

EV Charging Costs, PV Sales and Net Costs - Mean, SD (\$)

\begin{tabular}{|c|c|c|c|c|}
\hline \hline [Mean, SD] & AR & RND & IMM & OPT \\
\hline$S^{P V}$ & $4.41,2.81$ & $4.41,2.81$ & $4.41,2.81$ & - \\
\hline$C^{e v}$ & $8.21,3.21$ & $8.17,3.13$ & $7.32,3.87$ & $7.30,1.92$ \\
\hline$C^{\text {ar }}, C^{\text {imm }}, C^{\text {opt }}$ & $3.79,2.13$ & $3.75,2.07$ & $2.90,4.20$ & $-1.53,3.92$ \\
\hline$C_{\%}^{\text {imm }}, C_{\%}^{\text {opt }}(\%)$ & & & $31.72,61.26$ & $158.63,87.88$ \\
\hline
\end{tabular}
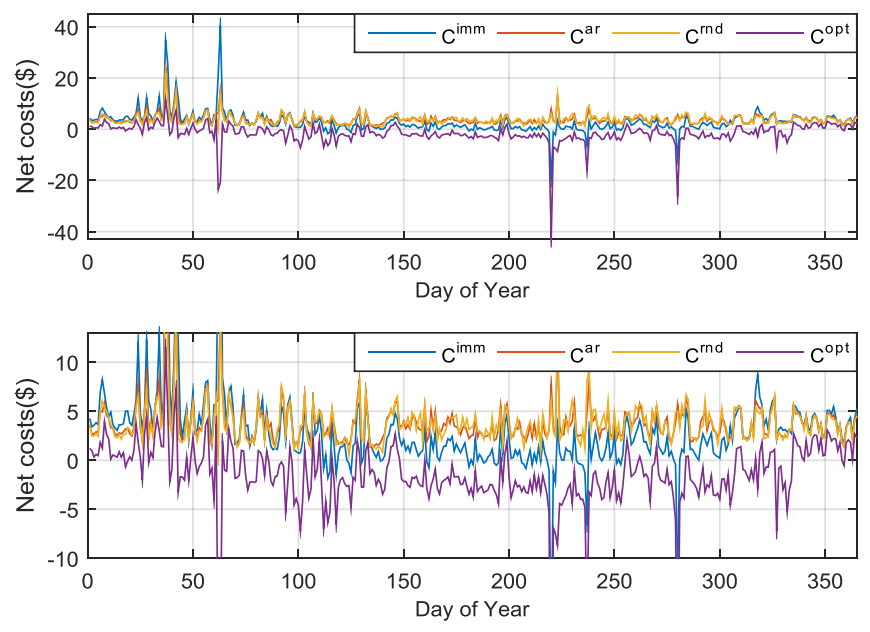

Fig. 5. Cost of charging the EV fleet by average rate, immediate and the proposed optimized charging strategy (top); zoomed view (bottom).

where $C^{e v}$ is the $\mathrm{EV}$ charging costs and $S^{P V}$ the revenues from PV sales. For AR, $x_{t, v}^{e+}=x_{v}^{e(a r)}$ and for IMM and RND, $x_{t, v}^{e+}=P_{c}^{E V r}$. With AR, RND and IMM, there is no provision to provide $\mathrm{V} 2 \mathrm{G}$, regulation services or multiplexing of chargers due to the absence of communication with an EMS. The peak power for the car park would be $60 \mathrm{~kW}$ for IMM, $20 \mathrm{~kW}$ for AR charging and between $20 \mathrm{~kW}$ to $60 \mathrm{~kW}$ for RND charging for $6 \mathrm{EVs}$ based on (1).

Fig. 5 and Table II shows the net costs $C^{a r}, C^{i m m}, C^{\text {rnd }}$ estimated for 2014 with the corresponding mean and standard deviation (SD). Four vital observations can be made. First, there is a large variation in net costs, ranging between $[1.35 \$$, $24.17 \$]$ and $[-19.58 \$, 40.43 \$]$ for AR and IMM, respectively. This is mainly due to the varying energy prices in ERCOT. The costs went negative for IMM on certain days indicating that the ESCo was paid by the ISO. It must be remembered that PV sales $S^{P V}$ for both strategies is the same as shown in Table II. Second, IMM charging was found to be better than AR in summer and vice versa in winter, with IMM charging net costs being cheaper than AR for 233 days. Third, the average net cost per day for 2014 for AR and IMM was found to be $3.79 \$$ and $2.90 \$$, with IMM being cheaper than AR by $31.7 \%$. This is because EVs are charged in morning for IMM when ERCOT prices are generally lower when compared to prices in the afternoon. Thus, for the given scenario it is found that IMM is better than AR. Fourth, the charging cost for randomly delayed charging is nearly the same as AR charging. This is because the process of randomly delaying the charging of individual EVs makes the net EV charging profile extended over the day, similar to AR charging.

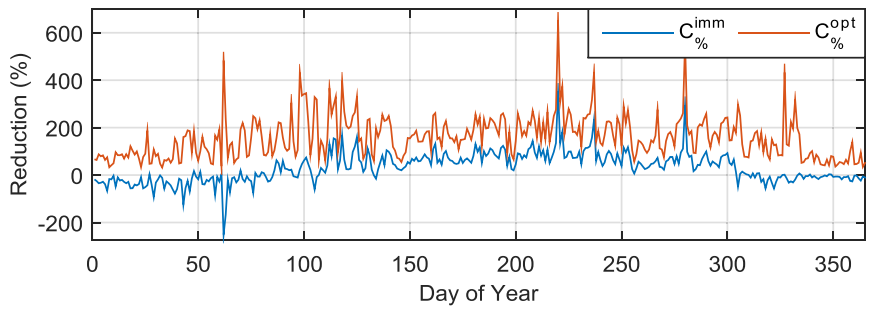

Fig. 6. Percentage reduction in the net cost for the proposed charging strategy and immediate charging with respect to average rate charging.

2) Optimized Net Costs: Using the MILP formulation for the optimized charging (OPT) described in Section III, the net costs $C^{o p t}$ are determined for each day of 2014 based on (39) and shown in Fig. 5 and Table II. The benefits of the MILP optimization can be clearly seen in the figure, where the optimized net costs are much lower than IMM and AR. $C^{\text {opt }}$ range is [-42.91\$, 11.56\$], which is much lower than IMM and AR. Due to the large penalty $C_{v}^{p}=1 \$ / \mathrm{kWh}, \mathrm{EVs}$ were always charged up to the required departure SOC by the departure time.

EV charging costs $C^{e v}$ (not net cost) are estimated separately for AR, IMM and OPT and shown in Table II. It can be seen that mean value of $C^{e v}$ is not that different between IMM and OPT. The reason is that the objective function is not optimized to reduce EV charging costs alone but rather to increase the sale of PV power and reserves as well.

The percentage reduction in net costs $C_{\%}^{i m m}, C_{\%}^{E V-P V}$ is estimated based on AR net costs $C^{a r}$ using (41)-(42) and shown in Fig. 6 for each day. $C^{a r}$ was chosen as a reference as the costs do not have values close to zero or go negative.

$$
\begin{aligned}
C_{\%}^{i m m} & =100\left(C^{a r}-C^{i m m}\right) / C^{a r} \\
C_{\%}^{o p t} & =100\left(C^{a r}-C^{o p t}\right) / C^{a r}
\end{aligned}
$$

As can be seen, the proposed optimized charging results in a cost reduction $C_{\%}^{\text {opt }}$ in the range of $32 \%$ to $651 \%$, with a mean of $159 \%$ with respect to AR charging. A reduction of $>100 \%$ should be interpreted as meaning that the net cost is negative. That is, the EV car park receives money for the EV charging, sale of PV and reserves rather than having to pay overall. This goes to show the big potential of the integrated EV-PV-V2G-regulation approach.

MILP solve times were in the range of 11.2-17.3s with a relative MILP gap of $0.015 \%$. The mean solve-time was $13.05 \mathrm{~s}$ with a standard deviation of $1.09 \mathrm{~s}$. A Windows PC with Intel Xeon 2.4Ghz CPU and 12GB RAM was employed.

\section{Case Studies}

Six case studies are performed in order to evaluate the net reduction in cost if only one or few of the smart charging applications are considered. Table III shows the six cases considered based on: the possibility for bidirectional charging $\left(x_{v}^{l b}=0\right.$ or not); if the EMS is provided input data for PV forecast $\left(y^{P V(f c)}=0\right.$ or not) and if the objective function optimizes based on the energy/regulation prices or not. For the cases that do not optimize based on the energy/regulation prices, the energy prices part (in red) and/or the regulation prices part (in blue) is removed in the objective function, (39). 
TABLE III

CASE STUdies CONSIDERING DIFFERENT SMART CHARGING APPLICATIONS

\begin{tabular}{|c|c|c|c|c|}
\hline \hline Case & $\begin{array}{c}\text { Bidirectional } \\
\text { V2G }\end{array}$ & $\begin{array}{c}\text { Energy } \\
\text { prices }\end{array}$ & $\begin{array}{c}\text { Regulation } \\
\text { services }\end{array}$ & $\begin{array}{c}\text { PV } \\
\text { forecast }\end{array}$ \\
\hline IMM/AVG & No & No & No & No \\
\hline Case 1 & No & No & Yes & No \\
\hline Case 2 & No & Yes & No & No \\
\hline Case 3 & No & Yes & Yes & No \\
\hline Case 4 & No & Yes & No & Yes \\
\hline Case 5 & Yes & No & Yes & Yes \\
\hline Case 6 & No & Yes & Yes & Yes \\
\hline OPT & Yes & Yes & Yes & Yes \\
\hline
\end{tabular}

TABLE IV

Reduction In Net Costs (\%) With Respect TO AVG FOR DIFFERENT CASES

\begin{tabular}{|c|c|c|c|c|c|c|c|}
\hline \hline Day & Case 1 & Case 2 & Case 3 & Case 4 & Case 5 & Case 6 & OPT \\
\hline 33 & 13.60 & 6.42 & 20.76 & 7.62 & 11.49 & 22.26 & 31.62 \\
\hline 83 & 38.83 & 12.81 & 57.71 & 19.75 & 30.90 & 65.81 & 96.73 \\
\hline 153 & 74.95 & 38.51 & 99.14 & 53.80 & 45.10 & 112.84 & 186.47 \\
\hline 220 & 239.96 & 205.76 & 355.53 & 244.61 & 451.93 & 376.11 & 650.83 \\
\hline 332 & 243.91 & 9.29 & 255.63 & 19.56 & 256.58 & 280.15 & 317.83 \\
\hline Avg. & 122.25 & 54.56 & 157.76 & 69.07 & 159.20 & 171.43 & 256.70 \\
\hline
\end{tabular}

For all the cases, the distribution network constraints, the EV user requirements and multiplexing of EVs is employed. Five sample days are considered and the percentage reduction in net costs with respect to AVG is estimated for all six cases, similar to Eqn. (42) as shown in Table IV. The average cost reduction for the five days considered is shown in the last row of the table.

From Table IV, it can be clearly seen that as more smart charging applications are included in the optimization, the net costs reduces drastically. For example, the cost reduction goes from $9.29 \%$ for case 2 to $317.83 \%$ for OPT, for day 332. In particular, the cost reduction for case 3 is always more than that for case 2 or case 1 , while the cost reduction for case 4 is always more than case 2 .

Case 6 and OPT differ on whether V2G is possible or not and this results in $(256.7-171.43)=85.2 \%$ reduction in net costs on an average for the given days, as seen in Table IV. Interestingly, it was found that no V2G energy was fed on the five days except for day 220 with EV3 delivering 7.42kWh. This means that the cost reduction was mainly due to the increased up-regulation power $x_{t, v}^{r(u p)}$ that was sold to the ISO on all five days. This goes to show that the main benefit of V2G is not always in energy sales but in increased regulation services offered as well.

To reiterate this point, the annual V2G energy fed to the grid for OPT was estimated and found to be $42.2 \mathrm{kWh}$. This is $0.072 \%$ of the total annual demand of the EVs of $365 * 80=$ $58,400 \mathrm{kWh}$. Combined V2G sales over the year was $13.14 \$$ or 3.6c/day, without considering the battery degradation penalty of $1.77 \$$. V2G occurred only on 7 days of the 365 days and 3 EVs out of 6 participated, largely discouraged by the battery degradation penalty, $C^{V 2 X}$.

\section{Inferences}

The large cost reduction is a hence result of aggregating the multi-aspect PV, EV, energy market problem into a single
MILP formulation. This results in the sale of PV and V2G power when prices are high, buying of EV charging power when prices are low and continuous sale of regulation services. The current MILP formulation is such that IMM, AR, RND or any of the cases will be a special case of optimized charging OPT as dictated by the PV forecast and market prices. Second, the sharing of a single charger to charge several EVs results in a reduction of charging infrastructure cost. While these costs have not be included in the estimate, they can be up to $15,000 \$$ for $10 \mathrm{~kW}$ chargers with $N_{c}^{c o n n}=4$.

Third, as with any forecasting and modeling, there will be small but finite errors in the PV forecasting and inaccuracies in the modeling of the EV and charger. The impact of the modeling and forecasting error is that it will lead to reduced revenues than what is estimated. It is also why only a fraction $\left(1-y_{P V}^{f c}\right)$ of the available reserves are guaranteed and sold to the ISO. The receding horizon approach that responds to changes in model parameters, including solar PV forecast, is hence used to reduce the impact of these errors. The impact of the errors can be further reduced with smaller time steps than $15 \mathrm{~min}$.

\section{E. Implementation Aspects}

In this section, the practical aspects of implementing this optimization are analyzed.

1) Adaptability: It must be kept in mind that even though wholesale DAM prices and small EV fleet have been used in this simulation, the formulation is generic to be used with large EV fleet, real-time market (RTM) and retail electricity prices as well. The parameters listed in the nomenclature section can be adapted for different markets, PV, EV types and to different smart charging scenarios as highlighted by the six case studies.

2) Capital Cost and Sharing of Benefits: The capital cost of building the proposed EV-PV integrated charging facility will be cheaper than a non-integrated system due to four reasons:

1) The integrated bidirectional EV-PV charger costs the same as the sum of the cost of buying a similarly rated solar inverter and unidirectional EV charger [35]. The benefit of integration is the bidirectional operation of $\mathrm{EV}$ at no additional cost, a smaller converter as it needs only one DC/AC inverter to the AC grid and no communication hardware needed between the EV and PV system.

2) The multiplexing system will allow the connection of a single charger to several EVs. This will drastically reduce the EV charging infrastructure cost by a factor proportional to how many cars are multiplexed to one charger.

3) The use of rolling horizon implementation as opposed to stochastic optimization to handle forecasting errors and uncertainties simplifies the formulation and reduces the computational complexity; hence less powerful and cheaper hardware can be used.

4) The integrated scheduling of EV-PV-V2G-regulation reduces the net costs on an average by $158 \%$ and this could provide a revenue stream to recover the capital cost. 
The EV-PV car park has several players involved namely the owner of PV and parking area, the ESCo, the ISO $\mathrm{EV}$ user and in a general scenario, the charge-point operator (CPO), e-mobility service provider (eMSP) and the DSO. The capital investment of the EV-PV charging facility and the benefit of the net cost reduction will ultimately have to be shared amongst all these parties. This will be dependent on the contractual business agreement between the parties.

3) Scalability: Similar to any MILP problem, the problem size will grow exponentially with the number of EV. At the same time, different parking locations are decoupled by their EV, PV and distribution constraints and hence the model dimension is naturally limited to the size of a single parking lot, about 5 to 1000 EVs. Thus, the MILP's dimensionality is limited to problem sizes that are tractable by the current technology and therefore fairly scalable. Further, the receding horizon implementation makes the problem more scalable in terms of computational complexity when compared to stochastic optimization.

Stochastic optimization is an alternative to the receding horizon approach. But we did not consider it here for two reasons. First, the given problem has a lot of stochastic variables, making it computationally intensive and hence less scalable. This is especially a problem as the number of $\mathrm{EV}$ grows to above 50 in a parking lot. The MILP formulation with receding horizon approach makes it computationally easier. Second, stochastic optimization requires generation of probabilistic data for all inputs and creating different scenarios for PV, EV and market. Due to limited EV penetration, there is insufficient data now on EV and EV user patterns creating lots of dimensions of uncertainty. If such limited data is used as input, it is difficult to get reliable and useful results.

4) Interaction With De-Regulated Energy Markets: With upto $1000 \mathrm{EVs}$ and $10 \mathrm{~kW}$ EV charger, the total car park is handling 10MW power at maximum, considering no multiplexing. This is small in relation to the power scales in the energy market. Hence, no perturbations will be observed on the market prices and no feedback on prices would be required for this system. At the same time, the net car park power can be occasionally lower than the minimum bid required by ISOs to participate in regulation services (for example, $0.1 \mathrm{MW}$ for PJM, 0.1MW for ERCOT and typically $1 \mathrm{MW}$ in other ISOs). It is expected that ISOs around the world would lower the minimum bid requirements in the future to allow EVs to participate in ancillary services.

\section{CONCLUSION}

EV charging from PV can be controlled to achieve several motives - to take advantage of time of use tariffs, provide ancillary services or follow the PV production. However, the common approach is that each of these applications is solved as separate optimization problems resulting in inconsistent charging profiles. This is impractical, as a single EV cannot be controlled at the same time with different charging profiles. Further, the economic befits of this approach are too small to warrant mass adoption of smart charging. Hence it is vital to make a single problem formulation that bundles several applications together so that one optimal EV charging profile with cumulated benefits is obtained.

In this paper, an MILP formulation has been proposed for charging of an EV fleet from PV that has several application built into one - charging of EV from PV, using time of use tariffs to sell PV power and charge EV from the grid, implementation of $\mathrm{V} 2 \mathrm{G}$ for grid support, using EV to offer ancillary services in the form of reserves and considering distribution network capacity constraints. The scheduling of the connection of a single EVSE to several EV has been included in the formulation. This provides the ability to share the EVSE amongst many EVs resulting in substantial reduction in the cost of EV infrastructure.

The MILP optimization has been implemented as a receding horizon model predictive control and operates with a fixed time period. Using 2014 data from Pecan Street Project and ERCOT market, simulations were performed for an EV fleet of six connected to four chargers. The formulation of five applications into one resulted in large reductions in the net costs in the range of $32 \%$ to $651 \%$ with respect to average rate charging. The net costs were far lower than those for immediate and randomly delayed charging, highlighting the benefits of the proposed smart charging algorithm.

Using six case studies, it has been shown that when several smart charging applications are combined together, it results in huge cost savings. Further, for the scenario simulated, it was observed that a large portion of the $\mathrm{V} 2 \mathrm{G}$ revenues came from increased regulation services offered rather than from V2G energy sales due to the battery degradation penalty. The MILP formulation is generic, scalable and can be adapted to different energy and ancillary markets, EV types, PV array installations and EVSE.

\section{ACKNOWLEDGMENT}

The authors would like to sincerely thank the support of G. M. Espana and D. van der Meer from the Delft University of Technology; Power Research Electronics B.V., Breda and ABB B.V., Rijswijk.

\section{REFERENCES}

[1] "Global EV outlook 2016," Int. Energy Agency, Paris, France, Tech. Rep., 2016. [Online]. Available: https://www.iea.org/ publications/freepublications/publication/Global_EV_Outlook_2016.pdf

[2] G. R. C. Mouli et al., "Economic and $\mathrm{CO} 2$ emission benefits of a solar powered electric vehicle charging station for workplaces in The Netherlands," in Proc. IEEE Transp. Electrific. Conf. Expo (ITEC), Dearborn, MI, USA, 2016, pp. 1-7.

[3] Efficiencies and CO2 Emissions From Electricity Production in The Netherlands, 2012 Update, Central Bureau Stat., The Hague, The Netherlands, 2014.

[4] D. P. Birnie, "Solar-to-vehicle (S2V) systems for powering commuters of the future," J. Power Sources, vol. 186, no. 2, pp. 539-542, Jan. 2009.

[5] X. Li, L. A. C. Lopes, and S. S. Williamson, "On the suitability of plug-in hybrid electric vehicle (PHEV) charging infrastructures based on wind and solar energy," in Proc. IEEE Power Energy Soc. Gen. Meeting, Calgary, AB, Canada, 2009, pp. 1-8.

[6] W. Kempton and J. Tomić, "Vehicle-to-grid power implementation: From stabilizing the grid to supporting large-scale renewable energy," J. Power Sources, vol. 144, no. 1, pp. 280-294, 2005. 
[7] H. Lund and W. Kempton, "Integration of renewable energy into the transport and electricity sectors through V2G," Energy Policy, vol. 36, no. 9, pp. 3578-3587, 2008.

[8] W. Kempton, V. Udo, K. Huber, K. Komara, and S. Letendre, "A test of vehicle-to-grid (V2G) for energy storage and frequency regulation in the PJM system," Dept. Center Carbon-Free Power Integr., Univ. Delaware, Newark, DE, USA, Tech. Rep., 2008. [Online]. Available: http://www1.udel.edu/V2G/resources/test-v2g-in-pjm-jan09.pdf

[9] P. J. Tulpule, V. Marano, S. Yurkovich, and G. Rizzoni, "Economic and environmental impacts of a PV powered workplace parking garage charging station," Appl. Energy, vol. 108, pp. 323-332, Aug. 2013.

[10] M. Kefayati and R. Baldick, "Harnessing demand flexibility to match renewable production using localized policies," in Proc. 50th Annu. Allerton Conf. Commun. Control Comput. (Allerton), Monticello, IL, USA, 2012, pp. 1105-1109.

[11] A. D. Hilshey, P. D. H. Hines, P. Rezaei, and J. R. Dowds, "Estimating the impact of electric vehicle smart charging on distribution transformer aging," IEEE Trans. Smart Grid, vol. 4, no. 2, pp. 905-913, Jun. 2013.

[12] Q. Gong, S. Midlam-Mohler, V. Marano, and G. Rizzoni, "Study of PEV charging on residential distribution transformer life," IEEE Trans. Smart Grid, vol. 3, no. 1, pp. 404-412, Mar. 2012.

[13] G. R. C. Mouli, J. Kaptein, P. Bauer, and M. Zeman, "Implementation of dynamic charging and $\mathrm{V} 2 \mathrm{G}$ using chademo and CCS/combo DC charging standard," in Proc. IEEE Transp. Electrific. Conf. Expo (ITEC), Dearborn, MI, USA, 2016, pp. 1-6.

[14] M. Caramanis and J. M. Foster, "Management of electric vehicle charging to mitigate renewable generation intermittency and distribution network congestion," in Proc. 48th IEEE Conf. Decis. Control (CDC) Held Jointly 28th Chin. Control Conf., Shanghai, China, 2009, pp. 4717-4722.

[15] M. Kefayati and C. Caramanis, "Efficient energy delivery management for PHEVs," in Proc. 1st IEEE Int. Conf. Smart Grid Commun., Gaithersburg, MD, USA, 2010, pp. 525-530.

[16] M. Kefayati and R. Baldick, "Energy delivery transaction pricing for flexible electrical loads," in Proc. IEEE Int. Conf. Smart Grid Commun. (SmartGridComm), Brussels, Belgium, 2011, pp. 363-368.

[17] T. Ma and O. A. Mohammed, "Optimal charging of plug-in electric vehicles for a car-park infrastructure," IEEE Trans. Ind. Appl., vol. 50, no. 4, pp. 2323-2330, Jul./Aug. 2014.

[18] T. Ma and O. Mohammed, "Economic analysis of real-time large scale PEVs network power flow control algorithm with the consideration of V2G services," in Proc. IEEE Ind. Appl. Soc. Annu. Meeting, Lake Buena Vista, FL, USA, 2013, pp. 1-8.

[19] Y.-M. Wi, J.-U. Lee, and S.-K. Joo, "Electric vehicle charging method for smart homes/buildings with a photovoltaic system," IEEE Trans. Consum. Electron., vol. 59, no. 2, pp. 323-328, May 2013.

[20] M. van der Kam and W. van Sark, "Smart charging of electric vehicles with photovoltaic power and vehicle-to-grid technology in a microgrid; a case study," Appl. Energy, vol. 152, pp. 20-30, Aug. 2015.

[21] N. Liu et al., "A heuristic operation strategy for commercial building microgrids containing EVs and PV system," IEEE Trans. Ind. Electron. vol. 62, no. 4, pp. 2560-2570, Apr. 2015.

[22] M. Honarmand, A. Zakariazadeh, and S. Jadid, "Integrated scheduling of renewable generation and electric vehicles parking lot in a smart microgrid," Energy Convers. Manag., vol. 86, pp. 745-755, Oct. 2014

[23] M. S. Kuran et al., "A smart parking lot management system for scheduling the recharging of electric vehicles," IEEE Trans. Smart Grid, vol. 6, no. 6, pp. 2942-2953, Nov. 2015.

[24] D. van der Meer, G. R. C. Mouli, G. Morales-Espana, L. R. Elizondo, and P. Bauer, "Energy management system with PV power forecast to optimally charge EVs at the workplace," IEEE Trans. Ind. Informat., to be published.

[25] L. Yao, Z. Damiran, and W. H. Lim, "Optimal charging and discharging scheduling for electric vehicles in a parking station with photovoltaic system and energy storage system," Energies, vol. 10, no. 4, p. 550, Apr. 2017.

[26] P. Sánchez-Martin, S. Lumbreras, and A. Alberdi-Alén, "Stochastic programming applied to EV charging points for energy and reserve service markets," IEEE Trans. Power Syst., vol. 31, no. 1, pp. 198-205, Jan. 2016.
[27] D. Wu, H. Zeng, C. Lu, and B. Boulet, "Two-stage energy management for office buildings with workplace EV charging and renewable energy," IEEE Trans. Transp. Electrific., vol. 3, no. 1, pp. 225-237, Mar. 2017.

[28] H. N. T. Nguyen, C. Zhang, and J. Zhang, "Dynamic demand control of electric vehicles to support power grid with high penetration level of renewable energy," IEEE Trans. Transp. Electrific., vol. 2, no. 1, pp. 66-75, Mar. 2016.

[29] E. Yao, V. W. S. Wong, and R. Schober, "Robust frequency regulation capacity scheduling algorithm for electric vehicles," IEEE Trans. Smart Grid, vol. 8, no. 2, pp. 984-997, Mar. 2017.

[30] J. Donadee and M. D. Ilić, "Stochastic optimization of grid to vehicle frequency regulation capacity bids," IEEE Trans. Smart Grid, vol. 5, no. 2, pp. 1061-1069, Mar. 2014.

[31] G. R. C. Mouli, P. Bauer, and M. Zeman, "Comparison of system architecture and converter topology for a solar powered electric vehicle charging station," in Proc. 9th Int. Conf. Power Electron. ECCE Asia (ICPE-ECCE Asia), Seoul, South Korea, 2015, pp. $1908-1915$

[32] H. Zhang, Z. Hu, Z. Xu, and Y. Song, "Optimal planning of PEV charging station with single output multiple cables charging spots," IEEE Trans. Smart Grid, vol. 8, no. 5, pp. 2119-2128, Sep. 2017.

[33] C.-Y. Chung, P. Chu, and R. Gadh, "Design of smart charging infrastructure hardware and firmware design of the various current multiplexing charging system," in Proc. 7th Glob. Conf., Prague, Czech Republic, 2013, pp. 25-27.

[34] G. R. C. Mouli, P. Bauer, and M. Zeman, "System design for a solar powered electric vehicle charging station for workplaces," Appl. Energy, vol. 168, pp. 434-443, Apr. 2016.

[35] V2G500V30A-10kW Bidirectional Solar EV Charger Module, Power Res. Electron. B.V., Breda, The Netherlands, and Delft Univ. Technol., Delft, The Netherlands, 2016.

[36] G. R. C. Mouli, J. H. Schijffelen, P. Bauer, and M. Zeman, "Design and comparison of a $10-\mathrm{kW}$ interleaved boost converter for PV application using $\mathrm{Si}$ and $\mathrm{SiC}$ devices," IEEE J. Emerg. Sel. Topics Power Electron., vol. 5, no. 2, pp. 610-623, Jun. 2016.

[37] C. Hamilton et al., "System architecture of a modular direct-DC PV charging station for plug-in electric vehicles," in Proc. 36th Annu. Conf. IEEE Ind. Electron. Soc. (IECON), Glendale, AZ, USA, 2010, pp. 2516-2520.

[38] G. Carli and S. S. Williamson, "Technical considerations on power conversion for electric and plug-in hybrid electric vehicle battery charging in photovoltaic installations," IEEE Trans. Power Electron., vol. 28, no. 12, pp. 5784-5792, Dec. 2013

[39] Plugs, Socket-Outlets, Vehicle Connectors and Vehicle InletsConductive Charging of Electric Vehicles-Part 1, 2, 3, IEC Standard 62196, 2014

[40] P. Bacher, H. Madsen, and H. A. Nielsen, "Online short-term solar power forecasting," Solar Energy, vol. 83, no. 10, pp. 1772-1783, Oct. 2009.

[41] M. Diagne, M. David, P. Lauret, J. Boland, and N. Schmutz, "Review of solar irradiance forecasting methods and a proposition for smallscale insular grids," Renew. Sustain. Energy Rev., vol. 27, pp. 65-76, Nov. 2013.

[42] Y. Cao et al., "An optimized EV charging model considering TOU price and SOC curve," IEEE Trans. Smart Grid, vol. 3, no. 1, pp. 388-393, Mar. 2012.

[43] M. A. Ortega-Vazquez, "Optimal scheduling of electric vehicle charging and vehicle-to-grid services at household level including battery degradation and price uncertainty," IET Gener. Transm. Distrib., vol. 8, no. 6, pp. 1007-1016, Jun. 2014

[44] S. B. Peterson, J. Apt, and J. F. Whitacre, "Lithium-ion battery cell degradation resulting from realistic vehicle and vehicle-to-grid utilization," J. Power Sources, vol. 195, no. 8, pp. 2385-2392, 2010.

[45] B. Lunz, Z. Yan, J. B. Gerschler, and D. U. Sauer, "Influence of plug-in hybrid electric vehicle charging strategies on charging and battery degradation costs," Energy Policy, vol. 46, pp. 511-519, Jul. 2012.

[46] L. De Vroey, R. Jahn, N. Omar, and J. Van Mierlo, "Impact of smart charging on the EV battery ageing-Discussion from a 3 years real life experience," in Proc. EVS28 Int. Elect. Veh. Symp. Exhibit. (KINTEX), Goyang, South Korea, May 2015.

[47] D. Wang, J. Coignard, T. Zeng, C. Zhang, and S. Saxena, "Quantifying electric vehicle battery degradation from driving vs. vehicle-to-grid services," J. Power Sources, vol. 332, pp. 193-203, Nov. 2016.

[48] Dataport, Pecan Street Inc., Austin, TX, USA, 2016. 


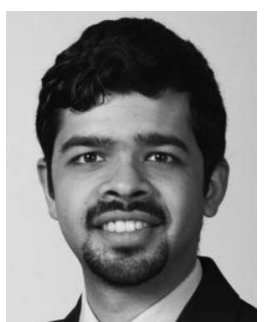

Gautham Ram Chandra Mouli (S'14) received the bachelor's and master's degrees in electrical engineering from the National Institute of Technology, Trichy, India, (Gold Medal) and the Delft University of Technology, The Netherlands (cum laude) in 2011 and 2013, respectively. Since 2013, he has been a Ph.D. Researcher with TU Delft, where he is a developing a bidirectional V2G charger for electric vehicles that is powered by solar panels. His research interest includes PV systems, power converters for EV charging and grid integration of distributed generation. He was a recipient of the Best Paper Prize at the IEEE INDICON Conference 2009, India, and the Best Poster Prize at the Erasmus Energy Forum 2016, The Netherlands. He has supervised several projects in TU Delft from 2013 to 2017 and two of them were awarded the UfD Cofely Energy Efficiency Prize 2014 and the Ward Vleugels Q-Park Thesis Award 2017.

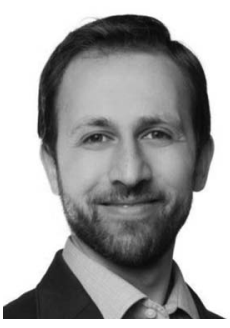

Mahdi Kefayati (S'01-M'14) received the B.Sc. degree in electrical engineering from the University of Tehran, Iran, in 2004, the M.S. degree in information technology engineering from the Sharif University of Technology, Iran, in 2006, and the M.S. and Ph.D. degrees in electrical engineering from the University of Texas at Austin, in 2012 and 2014, respectively, where he has been a Post-Doctoral Fellow since 2014. He served as a Research Intern with the Fujitsu Laboratories of America, CA, USA, in 2012. He has been with Electric Power Engineers Inc., since 2013, where he is currently a Senior Software Engineer.

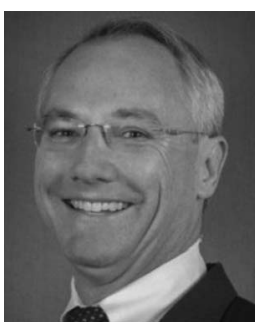

Ross Baldick (S'90-M'91-SM'04-F'07) received the B.Sc. degree in mathematics and physics and the B.E. degree in electrical engineering from the University of Sydney, Sydney, Australia, and the M.S. and Ph.D. degrees in electrical engineering and computer sciences from the University of California, Berkeley, CA, USA, in 1988 and 1990, respectively. From 1991 to 1992, he was a Post-Doctoral Fellow with Lawrence Berkeley Laboratory, Berkeley. In 1992 and 1993, he was an Assistant Professor with Worcester Polytechnic Institute, Worcester, MA, USA. He is currently a Professor with the Department of Electrical and Computer Engineering, University of Texas, Austin, TX, USA.

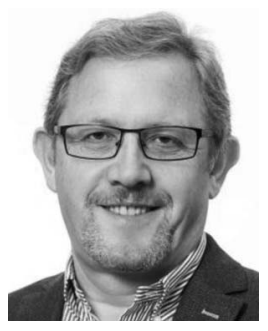

Pavol Bauer (S'91-M'00-SM'07) received the master's degree in electrical engineering with the Technical University of Kosice, 1985, and the Ph.D. degree from the Delft University of Technology, 1995, where he is currently a Full Professor with the Department of Electrical Sustainable Energy, and the Head of the DC Systems, Energy Conversion and Storage Group. From 2002 to 2003, he was partially with KEMA (DNV GL, Arnhem) on different projects related to power electronics applications in power systems. He published over 90 journal and over 300 conference papers with $\mathrm{H}$-factor Google scholar 33 citations and Web of science 21 citations. He has authored or co-authored eight books, holds four international patents, and organized several tutorials at the international conferences. He has researched on several projects for industry concerning wind and wave energy, power electronic applications for power systems, such as Smarttrafo; HVDC systems, projects for smart cities, such as PV charging of electric vehicles, PV and storage integration, contactless charging. He participated in several Leonardo da Vinci and H2020 EU projects as a Project Partner (ELINA, INETELE, and E-Pragmatic) and a Coordinator (PEMCWebLab.com-Edipe, SustEner, and Eranet DCMICRO). He was a recipient of Title Professor from the President of Czech Republic at the Brno University of Technology in 2008 and the Delft University of Technology in 2016. He is a former Chairman of the Benelux IEEE Joint Industry Applications Society and Power Electronics and Power Engineering Society Chapter, the Chairman of the Power Electronics and Motion Control Council, and a member of the Executive Committee of the European Power Electronics Association and International Steering Committee at numerous conferences. 